\title{
Accelerating population health improvement
}

\author{
Pedro Delgado and colleagues describe how applying improvement methods to working with \\ populations could help close equity gaps
}

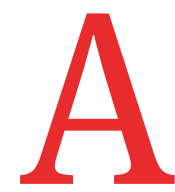

s the covid-19 pandemic shines a bright light on longstanding health equity gaps, ${ }^{1}$ concerted action around social determinants of health to close these gaps continues to increase. Improvement methods (including shared tools and language) traditionally used in healthcare are agnostic in nature and can also be used in sectors such as education, local government, law enforcement, and others to improve social determinants of health. Such adoption could catalyse population health improvement efforts with and for the populations they serve.

Three related concepts are core to this article. "Population health" is defined as the health outcomes of a group of individuals in a specified population, including the distribution of such outcomes within the group. "Population health management" efforts seek to optimise the health of populations over individual life spans. ${ }^{23}$ We did not find a common definition for "population health improvement," but we think this is an area that will start to generate more learning and evidence over the coming years. Ahead of such developments, we suggest an early definition: concerted, intentional, and systematic efforts by those working together towards measurable improvement of health and wellbeing outcomes, co-produced with and for the population in their locality. ${ }^{1}$

Actors jointly working to pursue better health for well defined populations

\section{KEY MESSAGES}

- Improvement methods traditionally used in healthcare can also be used by other actors outside healthcare working to improve population health

- The adoption of improvement methods by stakeholders working to improve population health has the potential to catalyse their joint efforts

- Using common implementation tools and language can help to achieve shared aims

- Population health improvement learning is likely to exponentially increase in months and years to come (including citizens, healthcare providers at all levels, councils or municipalities, businesses, schools, fire services, voluntary sectors, housing associations, social services, and police) will benefit from having a shared method that includes a common language and tools and can be applied across four areas: defining the system, describing shared aims and the work required to achieve them, measuring systematically over time, and acknowledging that change happens. These four components form the foundation of the improvement method, and their systematic application ${ }^{4}$ can bring health economy actors together in pursuit of better population health.

A common method to tackle shared challenges People are living longer; technology is evolving rapidly; and the costs associated with lack of proactive, concerted actions to prevent and manage non-communicable diseases have the potential to bankrupt healthcare systems and affect other sectors of the economy. With these drivers as a backdrop, several trends have taken shape in healthcare, including a shift towards tackling upstream factors, prevention, and self-management of conditions. ${ }^{5}$ Care models are shifting from specialized care to primary care, which has demanded the development of support systems, including use of technology to enable virtual care. ${ }^{56}$ Similarly, healthcare providers' priorities are shifting from volume to value, ${ }^{7}$ tackling quality and all of its dimensions ${ }^{5}$ and ensuring access to high quality care for all, with increased attention to inequities in outcomes for distinct populations.

Healthcare provider organisations are focused on partnering with citizens and communities to improve health and with patients to improve care. ${ }^{7}$ They are increasingly looking beyond the walls of their institutions to understand their effects more widely, ${ }^{8}$ with a greater awareness of the bi-directional connection between environmental changes and health, combining the concepts of planetary health and sustainability. ${ }^{9}$ There is a clear push towards health economy integration and place based health, ${ }^{1011}$ and organisations are making efforts to enhance the contribution of health systems as anchor institutions. $^{8}$

Building on these trends, governments have been promoting strategies to pursue better care and better health at sustainable costs. ${ }^{12-14}$ Health economies are therefore formally and informally fostering hands-on collaboration among traditional partners, such as healthcare institutions, and nontraditional partners, such as sectors related to the social determinants of health, to serve their local populations. In England, for example, the NHS is leading efforts to formalise collaboration by moving Integrated Care Partnerships into legislation by April 2022. ${ }^{15}$

As these partnerships form and evolve over time, a common improvement method (tools and language) provides a shared approach that stakeholders in and across sectors can use to translate strategy and evidence based changes, using local expertise, into measurable results.

\section{Strategies for population health improvement}

Box 1 shows priority areas and strategies for health systems to consider when undertaking population health improvement.

\section{Define and co-design}

Identify a group of people with similar needs or characteristics for whom a portfolio of interventions might improve outcomes. Start with the question, "Who is not thriving?" to identify broad populations, such as adult mental health or children and young people's health, and then select more specific population segments to focus improvement efforts by identifying an aim and changes to test, such as reducing suicide rates in men aged 16-24 in a particular geographical area. The King's Fund defines four interdependent pillars as the "system" of population health: individual health behaviour and choices; the places and communities that individuals live in and with; an integrated health and care system; and the wider determinants of health. ${ }^{16}$ These can be used to help define the population. A three part data review is also useful for population stratification to better understand the needs and assets of the population, which then inform the design choices to improve outcomes. ${ }^{17}$ 


\section{Box 1: Strategies for successful population health improvement}

Define the population and design accordingly
Develop bold ambitions and bold aims
Act with and for the population
Build a portfolio of projects focused on each population health aim
Segment for equity
Measure what matters
Embrace an asset based approach
Embrace humility to generate trust
Test your way into better partnership work, in pursuit of results
Make health improvement everyone's business and make improvement skills available to all

Bold ambitions for population health improvement need to be supported by aims that specify how much, by when, for whom, and where. Start by developing a bold purpose statement such as "being the best place to grow up. ${ }^{18}$ Next, create more specific and measurable aim statements that relate to the population rather than the service; for example, under the "best place to grow up" the vision could be " $90 \%$ of all children in each community planning partnership area will have reached all of the expected developmental milestones and learning outcomes by the end of primary school) by the end of 2021." Good aim setting will help identify opportunities to segment populations, establish relationships, and ensure that impact can be measured.

Co-design and co-production with individuals from the target population should be embraced at every step of the process. In population health improvement efforts, activating the agency of the population as well as that of those coordinating their care is fundamental. The process of working together towards the aim is as important as the aim itself and requires engaging key actors in the health economy (as described above), including citizens and service users, to design and adopt the changes needed to improve. People's health is heavily influenced by factors outside of their care such as their social and economic environment, physical environment, and individual characteristics and behaviours. ${ }^{19}$ So individuals are protagonists in efforts to improve population health, not passive "receivers" of health. Activating people's agency is at the heart of the Institute for Healthcare Improvement's Psychology of Change Framework. ${ }^{20}$ The framework describes methods and approaches around five inter-related domains of practice that organisations can use to advance and sustain improvement.

The complexity of the population health system is such that health economies will almost inevitably need a portfolio of projects occurring in parallel to make progress. Our experience emphasises the value of identifying key drivers for each aim and tackling them through targeted improvement projects, ensuring the efforts are also aligned with strategic priorities of these systems. "Think big and start small" is a mantra we often use.

\section{Partnering for equity}

There is no quality without equity. Stratifying data allows for better understanding of variation and gaps in outcomes, which in turn allows for tailoring strategies that respond to the specific needs of different populations to eliminate equity gaps. ${ }^{21}$ If a differentiated approach is not adopted, the gap between people who have access to the best possible health and those who do not will widen, leading to avoidable suffering, intergenerational cycles of poor health, and high costs for health economies. ${ }^{22}$ The World Health Organization defines equity as "the absence of avoidable, unfair, or remediable differences among groups of people, whether those groups are defined socially, economically, demographically or geographically, or by other means of stratification it implies that ideally everyone should have a fair opportunity to attain their full health potential and that no one should be disadvantaged from achieving this potential.,"23

Between 2017 and 2019, the Institute for Healthcare Improvement ran an initiative with eight health systems in the United States to improve equity in access to and quality of care, as well as health outcomes, through the practical application of improvement methods, collaboration, and shared learning. ${ }^{24}$ One key element was ensuring that health systems had the capacity to collect and stratify data to better understand which populations were benefitting and which ones were being left behind, including data about race, language, and ethnicity. This enabled health systems to create better solutions that took into consideration the specific needs and conditions of those left behind..$^{24}$

Health systems should proactively partner with individuals, communities, and institutions within and beyond healthcare. There is a growing realisation that the historical approach to health and healthcare, which is largely dependent on professionally trained and qualified health and healthcare "experts," needs to be reconsidered. The most successful population health improvement efforts involve actors that are open and willing to value each other's assets (such as will, abilities, and resources) and understand that the whole is greater than the sum of its parts.

Integration will move forward at the speed of trust. In the earliest stages, health economies that are learning to work together will require humility to accept that the protagonist is the citizen, not any single actor, and will require designing systems that are organized around the needs of those citizens. This is hard to do and must be intentionally designed early in the process to create an environment of psychological safety, to develop a sense of community guided by a unified purpose, and to foster trust and a set of behaviours that build trust, instil purpose, and generate energy. ${ }^{25}$ Municipal leaders from the Bridge for Better Health effort in Denmark have a performance indicator related to the quality of their relationships with partners as a way of focusing attention on humility and good collaboration. ${ }^{13}$

\section{Measure and learn}

Health systems should identify what matters most to the population of interest and develop measures to track progress. The large number of measures health systems are often required to track leads to diffusion of impact and exhaustion of staff, who find themselves collecting data for many indicators with little connection to the purpose of such efforts. ${ }^{26}$ More importantly, tracking too many measures might not directly benefit the people that health systems serve. Population health improvement efforts often struggle because health economy actors do not feel ownership of broad aims, and it is difficult to define who is responsible for achieving outcomes when data are collected. We foresee a future in which health systems will start to include other aspects in their measurement efforts: relationships between partners in the health economy and the environmental effects of the carbon footprint resulting from more 
home based health and care models, for example.

Avoiding planning paralysis is important. Too often, integration efforts in health economies dedicate a disproportionate amount of time and energy to establishing governance arrangements and idealised strategies and plans, without paying enough attention to how ambitions will be tested, implemented, and scaled up. Integration is frequently seen as an end in itself, when it's clearly a means to an end-measurable outcomes for better population health. We encourage testing and learning, from the integration process to implementing specific changes to improve population health. This iterative testing and learning approach enables refinement of the strategy and "the work" of improving population health, and it is a cornerstone of the improvement methods described above.

Improving population health starts and ends with each citizen. Making improvement everyone's business will create the opportunity to put improvement knowledge in their hands. We hope in the future that citizens will develop fluency in improvement methods and be able to design their personal health driver diagrams, to test changes in their own lives that are co-designed with members of their "life system," and to measure progress over time. The same principle applies to all health economy actors, who yield the benefit of having a common language for implementation to progress towards better population health. The jargon filled nature of improvement literature needs to be tackled to make the content accessible to citizens, families, health professionals, and other actors of health economies.

\section{Conclusion}

Covid-19 will continue to have a profound effect on the health of populations globally and is already challenging health systems to work agilely with local partners to better serve their communities. Our experience based reflections are offered as both a provocation and an invitation to stakeholders in population health improvement to adopt a common improvement method to accelerate progress. Furthermore, we think that clearly defining population health improvement as a field of learning can help those working towards better population health share lessons, successes, and opportunities from their efforts. We envision a future where systematic use of a shared improvement method will yield valuable lessons about improving population health, and a thriving population health improvement learning community will continue to grow in numbers and strength.

Contributors and sources: PD and JA have worked with partners across Latin America in population health improvement efforts including local municipalities, education, health services, citizens and others working together in pursuit of better outcomes. PD has also worked in the UK with partners in pursuit of better population health. AS has worked across East London NHS Foundation Trust and through the Royal College of Psychiatrists with a range of partners in pursuit of better care and health at sustainable costs, using improvement methods. KB is a practising GP, who is working in the community based partnership Bridges for Better Health in Region Sjaelland (Denmark) for better population health and health equity, applying improvement methods. JE is working in pursuit of better population health as the public health director in Region Jönköping County. JE is also leading the national initiative Strategy for health at the Swedish Association of Local Authorities and Regions (SALAR). DA is a consultant in public health medicine and works at Imperial College Healthcare NHS Trust and through the Health Foundation on efforts to improve population health.

Competing interests: We have read and understood $\mathrm{BMJ}$ policy on competing interests and have the following to declare: none.

This article is part of a series commissioned by The $B M /$ based on ideas generated by a joint editorial group with members from the Health Foundation and The BMJ, including a patient/carer. The BM/ retained full editorial control over external peer review, editing, and publication. Open access fees and The BMJ's quality improvement editor post are funded by the Health Foundation.

Pedro Delgado, vice president ${ }^{1,2}$

Kristine Binzer, general practitioner ${ }^{3}$

Amar Shah, chief quality officer ${ }^{4,5,6}$

Jesper Ekberg, public health director

Jafet Arrieta, senior director ${ }^{1}$

Dominique Allwood, assistant director improvement ${ }^{8,9}$

${ }^{1}$ Institute for Healthcare Improvement, Boston, MA, USA

${ }^{2}$ Harvard TH Chan School of Public Health, Boston, MA, USA

Bridge for Better Health, Region Sjaelland, Denmark ${ }^{4}$ East London NHS Foundation Trust, London, UK ${ }^{5}$ Royal College of Psychiatrists, London, UK ${ }^{6}$ University of Leicester, Leicester, UK

${ }^{7}$ Region Jönköping County, Jönköping, Sweden

${ }^{8}$ The Health Foundation, London, UK

${ }^{9}$ Imperial College London, London, UK

Correspondence to: P Delgado

pdelgado@ihi.org

Check for updates

This is an Open Access article distributed under the terms of the Creative Commons Attribution IGO License (https://creativecommons.org/licenses/ by-nc/3.0/igo/), which permits use, distribution, and reproduction for non-commercial purposes in any medium, provided the original work is properly cited.

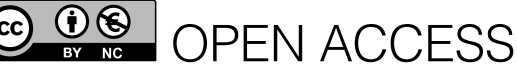

1 Marmot M. Health inequalities, covid-19, and healthcare professionals. Royal College of Physicians Blog; 2020. https://www.rcplondon.ac.uk/news/ health-inequalities-covid-19-and-healthcareprofessionals.

2 Kindig D, Stoddart G. What is population health? American Public Health Association, 2003, doi:10.2105/AJPH.93.3.380

3 Dahlgren G, Whitehead M. Tackling inequalities in health: what can we learn from what has been tried? Working paper prepared for The King's Fund International Seminar on Tackling Inequalities in Health. European Strategies for Tackling Social Inequities in Health. Vol 2. World Health Organization, 2007

4 The Triple Aim for ELFT. Quality Improvement. East London NHS Foundation Trust. 2019. https://qi.elft. nhs.uk/collection/the-triple-aim-at-elft/.

5 Institute of Medicine (US) Committee on Quality of Healthcare in America. Crossing the quality chasm: a new health system for the 21st century. National Academy Press, 2001.

6 Declaration of Astana. World Health Organization global conference on primary healthcare.

2019. https://apps.who.int/iris/bitstream/ handle/10665/328123/WHO-HIS-SDS-2018.61eng.pdf? sequence $=1$ \&isAllowed $=y$.

7 Stout S. Overview of SCALE and a Community of Solutions. SCALE 1.0 Synthesis Reports. Institute for Healthcare Improvement. 100 Million Lives Campaign. 2017. https://100mlives.org/downloads/ Overview-of-SCALE-Community-of-Solutions-7.7.17 final.pdf.

8 World Health Organization. Glossary of terms. 2010. https://www.who.int/hia/about/glos/en/index1. html.

9 The bigger picture of planetary health. Lancet Planet Health 2020;3. https://www.thelancet.com/journals/ lanplh/article/PIIS2542-5196(19)30001-4/fulltext.

10 Health and Social Care Integration Budgets. The Scottish Parliament. https://www.parliament.scot/ parliamentarybusiness/CurrentCommittees/100322 aspx.

11 NHS England. Local sustainability and transformation partnerships. https://www.england.nhs.uk/ integratedcare/stps/view-stps/.

12 NHS. The NHS long term plan. 2019. https://www. longtermplan.nhs.uk/.

13 Bridge to Better Health. Region Sjaelland Denmark. 2013. https://www.regionsjaelland.dk/Kampagner/ broen-til-bedre-sundhed/Materialer/Documents/ Broen\%20generelt/Broen\%20p\%C3\%A5\%20 engelsk.pdf.

14 Berwick DM, Learn PA, Gilmer TP, et al. The triple aim: care, health, and cost. Health Affairs. https://www. healthaffairs.org/doi/full/10.1377/hlthaff.27.3.759.

15 NHS England. Integrating care Next steps to building strong and effective integrated care systems across England. 2020. https://www.england.nhs.uk/ wp-content/uploads/2020/11/261120-item-5 integrating-care-next-steps-for-integrated-caresystems.pdf.

16 Diabetes. My Doctor Online. The Permanent Medical Group. https://mydoctor.kaiserpermanente.org/ncal/ diabetes/\#/?language=en

17 Triple Aim. How to undertake the 3 part data review. NHS East London. https://qi.elft.nhs.uk/wp-content/ uploads/2019/01/Three-part-data-review_ELFT_ v12.pdf.

18 The Scottish Improvement Journey. A nationwide approach to improvement. 2018. https:// www.gov.scot/binaries/content/documents/ govscot/publications/progress-report/2018/04/ scottish-improvement-journey-nationwideapproach-improvement-compiled-2016-17/ 
documents/00534268-pdf/00534268-pdf/ govscot\%3Adocument/00534268.pdf.

19 WHO. The determinants of health. 2010. https:// www.who.int/hia/evidence/doh/en/.

20 Hilton K, Anderson A. IHI psychology of change framework to advance and sustain improvement. Institute for Healthcare Improvement, 2018. http:// www.ihi.org/resources/Pages/IHIWhitePapers/IHIPsychology-of-Change-Framework.aspx.

21 Marmot M, Allen J, Boyce T, Goldblatt P, Morrison J. Health equity in England. 2020. https://www.health.org.uk/ publications/reports/the-marmot-review-10-years-on.
22 Achieving Health Equity. A guide for health care organizations. Institute for Healthcare Improvement, 2017. http://www.ihi.org/resources/Pages/ IHIWhitePapers/Achieving-Health-Equity.aspx.

23 WHO. Health equity. World Health Organization, 2017. https://www.who.int/topics/health_equity/en/.

24 Achieving Health Equity. A guide for health care organizations. Institute for Healthcare Improvement, 2017. http://www.ihi.org/resources/Pages/ IHIWhitePapers/Achieving-Health-Equity.aspx.

25 Cross R, Edmondson A, Murphy W. A noble purpose alone won't transform your company. MIT Sloan
Management Review. https://sloanreview.mit.edu/ article/a-noble-purpose-alone-wont-transform-yourcompany/.

26 Don Berwick. IHI National Forum keynote addresses. Quality, mercy, and the moral determinants of health. Institute for Healthcare Improvement, 2019. http:// www.ihi.org/resources/Pages/AudioandVideo/DonBerwick-National-Forum-Keynote-2019.aspx.

Cite this as: BMJ 2021;373:n966

http://dx.doi.org/10.1136/bmj.n966 